\title{
The Factors and Growth Mechanism for Smart City: a Survey of Nine cities of The Guangdong-Hong Kong-Macao Greater Bay Area
}

\author{
Minghua Jiang ${ }^{a}$, Xiao Luo ${ }^{b}$, Chengwen Chen ${ }^{c}$ \\ Department of Business Administration, City College of Dongguan University of Technology Dongguan, \\ Guangdong, China \\ a luchira@126.com, bluoxiao2755@126.com, cwencheng3@sina.com
}

Keywords: smart city; growing mechanism; social resource

\begin{abstract}
The concept of Smart City is changing the methods by which the cities manage urbanization strategies and govern city. The article on hand uses the dataset of nine cities of Guangdong, Southern province of China, to examine what social powers influent cities towards their smartness, and how they affect. It shows the influential social powers can be classified as four groups, personnel, capital, material and intellectual resources. After factor analysis, unit root test, cointegration test, Granger causality test and regression analysis, we found that, in the growth mechanism of smart city, the most important impetus force is financial resource, knowledge resource the second. Furthermore, in the progress towards smarter, the city will accelerate the accumulation of social resources. The results of this paper indicate the effect and efficiency of the strategy implementing in Guangdong Province.
\end{abstract}

\section{Introduction}

The concept of Smart City (SC), which was formed by IBM at the end of 2009, has been the subject of increasing attention and aroused heated discussion in urban planning, studying and governance worldwide. It not only extends the boundary of city's information process, also lamp the urbanization and industrialization of a modern community or region.

While a lot of Smart City projects are developing, many scientific research and studies have been realized. In the context of Smart City, the major research fields relate to the connotation of this concept, ways to establish, investment and operation model, influencing factors and evaluation criterion. However, little is known about the specific indicators of smartness and the powers to promote a city towards smarter. In particular, recently many literatures have shown that studying the growth mechanism of smart city will be very helpful to enhancing the accuracy of this concept.

In China, Smart City plays a crucial role while many cities in this country are energetically seeking a change in the model of economic growth. For the reason of being more competitive in operational cost and environment, all levels of city managers in China have applied the Smart City theory into their city management or, at least, have a plan of it. For example, Yangzhou and Changzhou had been authorized firstly as the two pilots of Smart City in China by Ministry of Industry and Information Technology (MIIT). By June of 2016, the pilot number of Smart City in the list of the MIIT has been up to 290. Nine cities of The Guangdong-Hong Kong-Macao Greater Bay Area (Guangzhou, Shenzhen, Zhuhai, Foshan, Huizhou, Dongguan, Zhongshan, Jiangmen and Zhaoqing, they all belong to Guangdong Province) are together on this list. The aim of this paper is to investigate the growth mechanism of nine cities towards smartness. By doing so, we want to explore the following issues by two steps: (1) What are the key social powers driving city towards smartness? (2) What is the growth mechanism when we observe the Smart City in a perspective of social resources?

This paper provides an empirical contribution to filling the gap of recent research about Smart City. Firstly, we develop an indicator to present the smartness of a city so that we can compare the smartness among cities. The most important aspect of such comparative studies is that cities can learn from each other and know where their weaknesses are and how serious it is. Secondly, we use 
material, capital, personnel and intellectual resource as the most common ways to represent the key powers of smartness so that we can address concerns about the fact that what initiatives should be taken in the smarter progress and what will they cost.

The second contribution of this paper is that we use time series data regression to test the growth mechanism of Smart City. By using information of nine cities between 1997 and 2016, we find that the more input of social resources, the smarter the city will be. This is direct evidence of Smart City's innovational strategy. In addition, we find that the strategic outcome will vary according to different power combination.

In the first part of this paper we present a review on the mechanism of Smart City and we discuss the key powers from the perspective of social resources. In the subsequent section, we create five indicators relates to Smart City and then imply these original indicators to propose a multivariable logarithmic linear regression model. We want to check the growing mechanism through the quantitative relations among the five indicators. To do so, we present the data and report the results of four test methods (Unit Root Test, Johansen Cointegration Test, Granger Causality Test, and Regression Analysis) used in this paper. Our conclusions are drawn in the last section.

\section{Literature Review on Smart City}

\subsection{The characterizing attributes of Smart City}

Irrespective of what the purpose is, this strategy - city is the leading role in industry, tourism, finance, high technology, facilities, education and environment - coexits with research of Smart City. In recent years, Smart City has gain absolute interest in the world. Although there is no consensus when it comes to what exactly Smart Cities are, they can be described as those that utilize information and communication technologies with the aim to increase the living quality of their inhabitants while providing sustainable development. According to European House-Ambrosetti [1], Smart Cities can be defined as a territories with high capacity for learning and innovation, which is built-in the creativity of the population, their institutions of knowledge creation and the infrastructure for communication and city management. Smart City is a sophisticated system that sense and act to the cities` data gathered from digital municipal networks, for example, sewers, parking spaces, community security camera, police monitor, traffic lights, etc. [2]. The role that a Smart City plays is to improving managerial productivity by facilitating city governors` decision-making, industry organizing, city planning and crisis management [3]. Furthermore, Smart City also means the changes to private funding methods as much as public [4]. These changes require city`s managers be more initiative in dealing their work schedules.

According to these views, Smart City is not identical to technology change, since Smart City means investments in human capital and changes in methods of city-managing. In other words, the adjective of "smart" refers to a capacity for living, communicating and learning by attracting and retaining valuable investment in a city`s infrastructure, but also a capacity of the government to spirit innovation by delivering services and information to local people.

\subsection{The descriptive index for smartness}

When came to describe the smartness of a city, only few works have been done. Griffinger measured the smartness by categorizing 6 dimensions and all the 6 dimensions include 74 indicators [5]. Unfortunately, this classification cannot present the smartness of a large city for these indicators cannot cover massive information inherent in a large city. In fact, the attempt to describe index for cities` smartness should bring not only data and information into consideration, but also environmental quality, governance efficiency, energy-saving, emission-reduction, regional economy, living standard and social life. Tranos and Gertner highlight that the term of "Smart City" holds a certain intellectual ability that addresses several innovative socio-technical and socio-economic aspects of growth [6].

Smart City proposed a new vision for future communities where new intelligent technological tools, services and applications are integrated in a unique platform, providing interoperability and 
coordination between these several sectors. So, these attributes of green, intelligent, energy-saving and economic development ought to be involved when we portray the smartness using some quantitative index.

\subsection{The growth mechanism of smart city}

The core of a mechanism is the driving powers and the functional paths. Many researchers agree that innovation should be the key powers as to how a city becomes smarter. It seems that innovation will be the leading power to driving a city towards smarter when the city developed into certain level when the inner growth dynamics dominate the city`s future [7]. European researchers have elaborated six cities` (Barcelona, Roman, Milan, Berlin, Paris and Cannes) growing modes driving by innovation and suggested an innovation-driving way by comparing the construction ways of these cities [8]. Recent literatures focus how policy solutions increase the mobility in a Smart City and then produce agglomeration effect [9]. So, many sociologists believe that public policies relating to environmental, industrial and municipal investments are the ultimate impetus to driving a city towards smarter.

Disagreement can arise, however. At present, transferring of smart city concept to urban development policies is at beginning, it is difficult to analyze the mechanism comprehensively. Therefore, when detail these social powers, analysis of the mechanism only agree that some different social powers should be taken count in.

\section{Methodology and results}

\subsection{Data}

The dataset collected in this paper is time series annually, it consists 20 years information of nine cities. The advantage of this dataset is that it contains detailed information on the city`s history, a feature that is very desirable in the analysis presented here. These nine cities, Guangzhou, Shenzhen, Zhuhai, Foshan, Huizhou, Dongguan, Zhongshan, Jiangmen and Zhaoqing, all around Pearl River entrance, where is called The Guangdong-Hong Kong-Macao Greater Bay Area. By 2016, all these cities had been list as pilot cities by MIIT. Innovations are chosen as the driving force when these cities made their smart city strategies. The success of these cities made Guangdong the leading province in smart city in China. Accordingly, in this paper, these nine cities have been selected to be the examples for the study of growth mechanism of Smart City. The data covers from 1997 to 2016. All the data come from Statistical Yearbook of Guangdong (1997-2016) and the Yearbook of Science and Technology of China(1997-2016).

\subsection{Descriptive Index}

The purpose of this article is to discuss what the growth mechanism is when the city is driven towards smarter by social resources, so the first step is to choose index to represent the social resources invested in a city. This article selects four indexes, which include number of scientific and technological personnel, R\&D spendings, number of scientific institution and number of pending patents, to represent respectively personnel resource (PI), capital resource (CI), material resource (MI) and intellectual resource (II) that invested in a city.

Now, there are different methods suggested in literatures when it comes to how to measure the smartness of a city [10]. According to the actual situation, Chinese researchers describe the smartness in somewhat different way. Li and Deng structure an evolutional index system which includes ubiquitous network, intellectual application, public supporting platform and economy achievement [11]. Liu and Zheng evaluated the potential of smart city in infrastructure construction, public supporting platform, urban competitiveness and economy achievement [12].

In this paper, we believed that the descriptive index of smartness should involve the dimensions of infrastructure construction, public supporting platform, urban competitiveness, regional economy and environmental protection. So we selected number of Broadband Internet users, patent licensing, registered private enterprise, city`s GDP and carbon emission to measure the smartness of a city. 
This study creates an indicator of smartness level (SL) by applying the technique of factor analysis: through factor analysis and common factor extracting, the five index (number of Broadband Internet users, number of patent licensing, number of registered private enterprise, regional GDP and carbon emission levels) are attributed to one factor-the smartness level of the city. Table 1 shows the structure of our descriptive index system.

Tab.1 the structure of the index system

\begin{tabular}{l|l}
\hline \multicolumn{1}{c|}{ variable } & \multicolumn{1}{c}{ description } \\
\hline & (1)number of Broadband Internet users, \\
(2)number of patent licensing \\
(3)number of registered private enterprise \\
(4)regional GDP \\
(5)carbon emission levels \\
personnel resource (PI) & number of scientific and technological personnel \\
capital resource (CI) & R\&D spendings \\
material resource (MI) & number of scientific institution \\
intellectual resource (II) & number of pending patents \\
\hline
\end{tabular}

\subsection{Basic model}

The focus of this paper is to investigate the determinants of smart city. The model which has been extensively used in the literature has included various determinative powers of smart city such as the innovational resources like material, capital, personnel and intellectual resource. Based on the data availability and the empirical literature, this paper formulated a econometric model as following:

\section{LnSL=a+b1LnPI+b2LnCI+b3LnMI+b4LnII （1）}

In equation (1), SL is the variable measures the growth level of smart city, or smartness of a city. The variables of PI, CI, MI and II represent respectively personnel, capital, material and intellectual resources that the city`s managers invest into the city for the purpose of smarter. The constants of a, b1 b2、 b3 and b4 are parameters of the regression model, and they describe the directions and strengths of relationship between SL and the impetus resources invested in.

\subsection{Unit root test}

It is extremely important that the data we used is a stationary process because we will find spurious relationship of the variables in regression process when the dataset is not stationary. The process of unit root will be helpful in checking the stationarity before we use the dataset in subsequent analysis. In this paper, augmented Dickey-Fuller(ADF) unit root process has been employed for this purpose. The test covers all the variables (SL, PIR, CIR, MIR and IIR) and the result is summarized in Table 2 . In table 2, test statistics and critical values are given. When the variable is in the second difference, the ADF test statistics calculated for LnSL is -4.9224. The critical values are $-3.7073,-3.3242$, and -2.0543 in order for $1 \%, 5 \%$ and $10 \%$ significant level. The test statistic is less than all critical values, so we can reject the null hypothesis that the Shenzhen series contains a series of unit roots. Similarly, we can get the same conclusions when we check the rest variables like LnMI, LnCI, LnPI and LnII. So, from this table, we can find that all the variables in this model are stationary in the second difference or $\mathrm{I}(2)$.

Tab. 2 Results of ADF Unit Root Test

\begin{tabular}{ccccccc}
\hline Var & Diff & ADF & $1 \%$ CV & $5 \%$ CV & $10 \%$ CV & Type \\
\hline LnSL & 2 & -4.9224 & -3.7073 & -3.3242 & -2.0543 & $\mathrm{I}(2)$ \\
LnMI & 2 & -4.6966 & -3.5784 & -2.8776 & -2.2334 & $\mathrm{I}(2)$ \\
LnCI & 2 & -4.1086 & -3.5784 & -2.8776 & -2.2334 & $\mathrm{I}(2)$ \\
LnPI & 2 & -4.4654 & -3.5784 & -2.8776 & -2.2334 & $\mathrm{I}(2)$ \\
LnII & 2 & -5.0763 & -3.5784 & -2.8776 & -2.2334 & $\mathrm{I}(2)$ \\
\hline
\end{tabular}

\subsection{Cointegration test}

In order to determine the long term relationship between LnSL and each of the rest four variables 
(LnMI, LnCI, LnPI and LnII), cointegration test is performed. This paper, Johansen approach is used to check whether there are log-run relationship between the dependent variable and the independent one. Table 3 shows the results of Johansen process. According to the result of eigenvalue test shown in the second row, we can reject the null hypothesis that there is none long run relationship between all variables, and the third row of this table substantiate us to reject the null hypothesis that there is at most one cointegrating relationship among these five variables. However, we cannot reject the null hypothesis that there are at most two or three cointegrating relationship among these variables. Therefore, we can say that there is at least one cointegrating relationship among these variables.

Tab. 3 Results of Johansen Cointegration Test

\begin{tabular}{ccccc}
\hline Hypothesized & Eigenvalue & Statistic & $5 \%$ CV & Prob \\
\hline None* & 0.8099 & 57.4566 & 33.6722 & 0.000 \\
At most 1* & 0.7233 & 24.8465 & 21.3346 & 0.000 \\
At most 2 & 0.6012 & 7.0425 & 12.5432 & 0.067 \\
At most 3 & 0.0422 & 1.1411 & 4.6541 & 0.345 \\
\hline
\end{tabular}

*:significance at $5 \%$ level

\subsection{Granger causality test}

The cointegration process showed only the existence of long-run relationship among the five variables, but it cannot tell us where this relationship is. The Granger approach can help us in predicting the relationship occurs in which pair of variables. Vector autoregressive model (VAR) will be used when we proceed Granger approach. To see the robustness of the results of VAR model, we should estimate its lag-interval firstly. The results are shown in table 4 . We find that all criteria (LR, FTE, AIC and HQ) are significant in the level of 5\% if we choose 3 as the lag interval. So, we decide that the lag interval for the VAR is 3.

Tab. 4 Results of Lag Length of VAR

\begin{tabular}{ccccc}
\hline Lag & LR & FTE & AIC & HQ \\
\hline 0 & NA & 0.000045 & -3.423131 & -3.403424 \\
1 & 421.4332 & $3.35 \mathrm{e}-08$ & -8.210401 & -8.140202 \\
2 & 32.30206 & $2.34 \mathrm{e}-09$ & -9.13302 & -8.403141 \\
3 & $26.30234^{*}$ & $3.18 \mathrm{e}-09^{*}$ & $-10.06332^{*}$ & $-8.899651^{*}$ \\
4 & 43.77654 & $4.66 \mathrm{e}-09$ & -12.88765 & -9.930886 \\
\hline
\end{tabular}

Tab. 5 Results of Granger causality test

\begin{tabular}{ccccc}
\hline $\mathrm{H}_{0}{ }^{*}$ & Lag Interval & F-Statistic & Prob. & $\begin{array}{c}\text { Accept } \mathrm{H}_{0} \text { or } \\
\text { not }\end{array}$ \\
\hline LnSL - LnMI & 3 & 3.88765 & 0.3005 & yes \\
LnSL - LnCI & 3 & 6.28767 & 0.0060 & no \\
LnSL - LnPI & 3 & 2.99812 & 0.4432 & yes \\
LnMI - LnII & 3 & 4.32199 & 0.0007 & no \\
LnMI - LnCI & 3 & 0.87763 & 0.7600 & yes \\
LnMI - LnPI & 3 & 0.62123 & 0.5498 & yes \\
LnMI - LnII & 3 & 0.85507 & 0.1197 & yes \\
LnCI - LnSL & 3 & 0.75556 & 0.1229 & yes \\
LnCI - LnMI & 3 & 0.56489 & 0.2386 & yes \\
LnCI - LnPI & 3 & 0.23114 & 0.6589 & yes \\
LnCI - LnII & 3 & 0.63861 & 0.6256 & yes \\
LnPI - LnSL & 3 & 0.87449 & 0.5488 & yes \\
LnPI - LnMI & 3 & 0.77098 & 0.4344 & yes \\
LnPI - LnCI $-L n I I$ & 3 & 0.76889 & 0.6754 & yes \\
LnII - LnSL & 3 & 0.23155 & 0.3211 & yes \\
LnII - LnMI & 3 & 0.76548 & 0.6577 & yes \\
LnII - LnCI & 3 & 5.98865 & 0.6654 & yes \\
LnII - LnPI & 3 & 4.66412 & 0.4598 & yes \\
\hline
\end{tabular}

\footnotetext{
* :the null hypothesis is that $\mathrm{x}$ does not Granger-cause $\mathrm{y}$.
}

**:significance at 5\% leve

Given the lag interval (it is 3) and the null hypothesis that x does not Granger-cause y, this study 
carried out Granger causality tests for 15 groups of variables, and the result is shown as Table 5 . In this table, we reject the null hypothesis that LnSL does not Granger-cause LnCI and the null hypothesis that LnSL does not Granger-cause LnII. So we conclude that smartness level influence on the capital and intellectual resources invests in a city as innovational resource.

\subsection{Parameter estimate}

According to the results of unit boot test, Johansen cointegration test and Granger causality test, we carry out regression analysis to equation (1) by Eviews6.0. The results are demonstrated in Table 6. Using the data in table 6, the estimated model is equation (2):

LnSL=6.613438+0.044140LnMI+0.725961LnCI+0.005540LnPI+0.177745LnII

The value of F-statistic for this regression model is 10705.24 and the probability is 0.00000 , so we can get that not all coefficients of the model is zero. The probabilities of t-test for LnCI and LnII are 0.0075 and 0.0013 respectively, and both are significant at approximately the $5 \%$ significance level. Otherwise, the probabilities of t-test for LnMI and LnPI are 0.0553 and 0.8298 respectively, and both are not significant at approximately the 5\% significance level. Consequently, we can say that the main powers to drive the growth of a smart city are capital and intellectual innovative resources that invested in it.

Tab. 6 Results of regression analysis

\begin{tabular}{ccccc}
\hline Variable & Coefficient & Std. Error & t-Statistic & Prob. \\
\hline$a$ & 6.613438 & 0.531380 & 12.44577 & 0.0000 \\
LNMI & 0.044140 & 0.112796 & 2.164448 & 0.0553 \\
LNCI & 0.725961 & 0.226182 & 3.209635 & 0.0075 \\
LNPI & 0.055540 & 0.070721 & 0.219740 & 0.8298 \\
LNII & 0.177745 & 0.076799 & 0.100842 & 0.0013 \\
\hline R-squared & 0.999720 & Mean dependent var & 11.61883 \\
Adjusted R-squared & 0.999626 & S.D. dependent var & 0.805023 \\
S.E. of regression & 0.015559 & Akaike info criterion & -5.248437 \\
Sum squared resid & 0.002905 & Schwarz criterion & -5.003375 \\
Log likelihood & 49.61172 & Hannan-Quinn criter. & -5.224078 \\
F-statistic & 10705.24 & Durbin-Watson stat & 1.794976 \\
Prob(F-statistic) & 0.000000 & & \\
\hline
\end{tabular}

\section{Conclusions}

Smart city is of future-oriented and the concept of smart city is attracting increasingly attention from politicians, governors and academics over China. In this paper we have shown how city's resources facilitate nine cities to smarter. We construct a time series model select a dataset of nine cities in Guangdong from 1997 to 2016. And then we inspect the model by unit root test, cointegration test and Granger causality test. At last, regression analysis is used to determine how the social resources boost the growth of smart city of these cities, in other words, the mechanism of city to be smarter.

First of all, based on this paper, we believe that regional social resources perform as the driving powers in the process of a city to growing smarter. These innovational impetuses primarily include material resource, capital resource, personnel resource and intellectual resource. The result of the tests in this paper proved that there is, at least, one cointegration relationship among the five resources, which confirmed that the growth of smart city is driven mainly by social resources-material, capital, personnel, and intellectual resource. Therefore, it is necessary to rethink the strategies we have learned from traditional urbanization. Nowadays, the driving powers of urbanization have been changed, from traditional factors such as labor force and land to factors such as knowledge, information and technology. The progress of smart city must be supported by technological innovation, organizational innovation and service mode innovation. Then, the smart technology, such as cloud computing and big data, will be applied widely. In turn, the smart industries will begin to boom and the city's development mode will be changed.

Secondly, the capital resource is chiefly the power driving the growth of smart city among the four resources. The result of time series regression analysis showed that the coefficients of capital 
resource and intellectual resource is 0.725961 and 0.177745 respectively, and they are statistical significant at the level of 0.05. Thus, it is testified that the capital resource makes the biggest contribution driving the growth of smart city, followed the intellectual resource. These two resources account for almost $90 \%$ of the driving power to smart city. The capital resource driving the growth of smart city includes primarily the money invested by government and the private capital. Therefore, in one hand, government's investments should play an leading role of guidance as well as leverage. In other hand, it is necessary and urgent to consummate a profit contribution mechanism so that the private capital can be encouraged to be an active participant in the construction of smart city.

Finally, when a city grows towards smartness, it tends to attract more and more investment of capital innovative resource and intellectual innovative resource, the consequence of which will probably be a "Matthew Effect" and therefore cause imbalance in the progress of urbanization in China. In fact, this imbalance already exists: more and more people is moving from the left to the right of the line connecting Heihe to Tengchong. So that, it is obliged to reduce the inequality in the program of smart city. The sustainable development of smart city should be based on the difference of cities' resources, realizing the difference-complementary and cooperation of urban agglomerations.

\section{Acknowledgements}

The ideas in this paper arise from the project of the Study of Upgrading of Greater Town in Guangdong in the Background of The Guangdong-Hong Kong-Macao Greater Bay Area which is funded by Guangdong Provincial Educational Department (Award No. 2017WTSCX134).

\section{References}

[1] The European House-Ambrosetti. Smart cities in Italy: An oppor-tunity in the spirit of the Renaissance for a new quality of life. Available fromhttp://www.ambrosetti.eu/en, 2012.

[2] R. Hall, The vision of a smart city. In 2nd International life extension technology workshop, September 2000, Paris, France.

[3] B. Kortuem, F. Kawsar, D. Fitton, V. Sundramoorthy, "Smart Objects as Building Blocks for the Internet of Things”, Internet Computing, vol. 14, no. 1, pp. 44-51, 2010.

[4] G. Belli, G. Brusco, A. Burgio, M. Motta, D. Menniti, A. Pinnarelli, N. Sorrentino, "An energy management model for energetic communities of Smart Homes: The Power Cloud", Networking Sensing and Control (ICNSC) 2017 IEEE 14th International Conference on, pp. 158-162, 2017.

[5] R. Giffinger \& G. HaindlmaierSmart, "Cities ranking: an effective instrument for the positioning of the cities?” ACE: Architecture, City and Environment, vol.23, 2010, pp. 7-26.

[6] E. Tranos \& D. Gertner, "What are smart networked cities?" The European Journal of Social Science Research, vol.25, 2009 pp. 175-190.

[7] R. Hollands, "Will the real smart city please stand up? Intelligent, progressive or entrepreneurial?”, City, vol.12, 2008, pp. 303-320.

[8] C. Giovannella “Territorial Smartness and Emergent Behaviors”, ICSCS 2013, IEEE publisher, 2013, pp. 170-176

[9] E. McCann, "Urban policy mobilities and global circuits of knowledge: toward a research agenda”, Annals of the Association of American Geographers, vol.101, 2011, pp. 107-130.

[10] M. Hernandez, "smart cities, the silent IoT revolution" Telefonica Investigation, S.A. Unipersonal 2010, December 2010.

[11] Xianyi Li,Xiaoyu Deng(2011). “The Study of Criteria System for Smart City”. Telecommunications Network Technology,2011(10):43-47.

[12] Xiaoyin Liu, Shurong Zheng(2013). "Evaluation of Smart City Development Potential in East Region of China”.Science and Technology Manangement Research,2013(22):75-79. 